\title{
USO E COBERTURA DO SOLO PARA O PLANEJAMENTO URBANO, BOA VISTA, RORAIMA, BRASIL
}

\author{
LAND USE AND COVER FOR URBAN PLANNING, \\ BOA VISTA, RORAIMA, BRASIL \\ USO Y COBERTURA DEL SOLO PARA PLANIFICACIÓN \\ URBANA, BOA VISTA, RORAIMA, BRASIL \\ Antônio Carlos Ribeiro Araújo Júnior - Universidade Federal de Roraima - Roraima - Boa Vista - Brasil \\ aj_geo@hotmail.com
}

\begin{abstract}
Stélio Soares Tavares Júnior - Universidade Federal de Roraima - Roraima - Boa Vista - Brasil stelio.tavares@ufrr.br
\end{abstract}

\section{Resumo}

Boa Vista, capital do estado de Roraima segundo dados do Instituto Brasileiro de Geografia e Estatística (IBGE) passou de uma população de cerca de 67 mil pessoas na década de 1980 para cerca de 320 mil em 2015, demonstrando um amplo crescimento populacional. 0 processo de ocupação do estado de Roraima está concentrado na cidade de Boa Vista, a qual aglutina $86,62 \%$ da população, sendo necessário analisar como 0 uso e cobertura do solo são ferramentas necessárias para entender 0 incremento populacional e, assim, melhor planejar os usos futuros do espaço boavistense, visto que recursos naturais como corpos d'água e vegetação nativa estão se perdendo no processo de ocupação. 0 uso de geoprocessamento e sensoriamento remoto foram importantes instrumentos de análise e permitiram constatar que (i) muito já se perdeu em termos de recursos naturais no processo de uso e ocupação, mas (ii) ainda há planejamento possível sem maiores perdas.

Palavras-chave: Sociedade, natureza, espaço, geoprocessamento, urbanização.

\begin{abstract}
Boa Vista, capital of Roraima state according to data from the IBGE - Brazilian Institute of Geography and Statistics increased its population from about 67,000 people in the 1980s to around 320,000 in 2015 demonstrating a wide population growth. Because the process of occupation of the state of Roraima is concentrated in the city of Boa Vista, which agglutinates $86,62 \%$ of this population, it is necessary to examine how land use and cover are necessary tools to understand the population increase and thus better plan future uses of boavistense space, since natural resources such as water bodies and native vegetation are being lost in the process of occupation. The use of geoprocessing and remote sensing were important tools for the analysis and allowed to observe that (i) much has been lost in terms of natural resources in the use and occupation process, but (ii) there are still possible planning without major losses.
\end{abstract}

Keywords: Society, nature, space, geoprocessing, urbanization.

\section{Resumen}

Boa Vista, capital del estado de Roraima, según datos del Instituto Brasileño de Geografía y Estadística pasó de una población de cerca de 67 mil personas, en la década de 1980, para alrededor de 320 mil en 2015, mostrando un amplio crecimiento de la población. El proceso de ocupación tomó el rumbo de la ciudad de Boa Vista, que concentra $86,62 \%$ de esta población, siendo necesario examinar cómo el uso y cobertura del suelo 
son herramientas necesarias para entender el aumento de la población y, de esa forma, planificar los usos futuros del espacio boavistense, ya que los recursos naturales, tales como los cuerpos de agua y la vegetación nativa se están perdiendo en el proceso de ocupación. El uso de geoprocesamiento y la teledetección fueron importantes instrumentos de análisis instrumental y permitieron demostrar que (i) se ha perdido mucho en términos de recursos naturales en el proceso de uso y ocupación, pero (ii) todavía es posible la planificación sin grandes pérdidas.

Palabras clave: Sociedad, naturaleza, espacio, geoprocesamiento, urbanización.

Introdução

Nos últimos 30 anos, a cidade de Boa Vista no estado de Roraima passou por intenso processo de expansão urbana. Segundo dados do Instituto Brasileiro de Geografia e Estatística (IBGE, 2016), na década de 1980 o município contava com 67.017 habitantes. No ano de 2015 este quantitativo representa 320.714 habitantes, dos quais 277.799 habitantes viviam na zona urbana e 42.915 na zona rural, ou seja, 86,62\% da população vive no espaço urbano consolidado de Boa Vista.

A cidade de Boa Vista precisa de mecanismos objetivos que tomem por base seu espaço urbano consolidado e áreas em processo de consolidação (Fig. 1) para de fato ordená-la socialmente, considerando os elementos físicos pertencentes a este espaço, pois esses são recursos naturais autóctones necessários para a manutenção do bem-estar social e não geração de impactos nocivos a médio e longo prazo à sociedade.

Segundo Joly (1990) analisar o espaço geográfico não é um simples exercício de estilo nem um divertimento: é uma operação que normalmente se inscreve num processo de pesquisa científica ou de organização territorial. Um mapa não é apenas uma obra de arte, é um instrumento de descoberta e de comunicação a serviço de um saber ou uma ação.

Para tanto, Fitz (2008a) diz que antes de um uso direto e simplista de técnicas cartográficas, deve-se ter um bom conhecimento das complexidades e potencialidades dos produtos obtidos, uma vez que o uso incorreto dos dados contidos em uma carta, mapa etc., poderá causar um resultado desastroso, mesmo estando esteticamente agradável.

Imagens de sensores remotos ${ }^{1}$ são importante fonte de dados da superfície terrestre, sendo cada vez mais utilizadas para a elaboração de diferentes tipos de mapas após interpretação, pois segundo Florenzano (2002) no processo de interpretação, dados contidos em uma imagem são transformados em informação e apresentados em forma de mapa. 


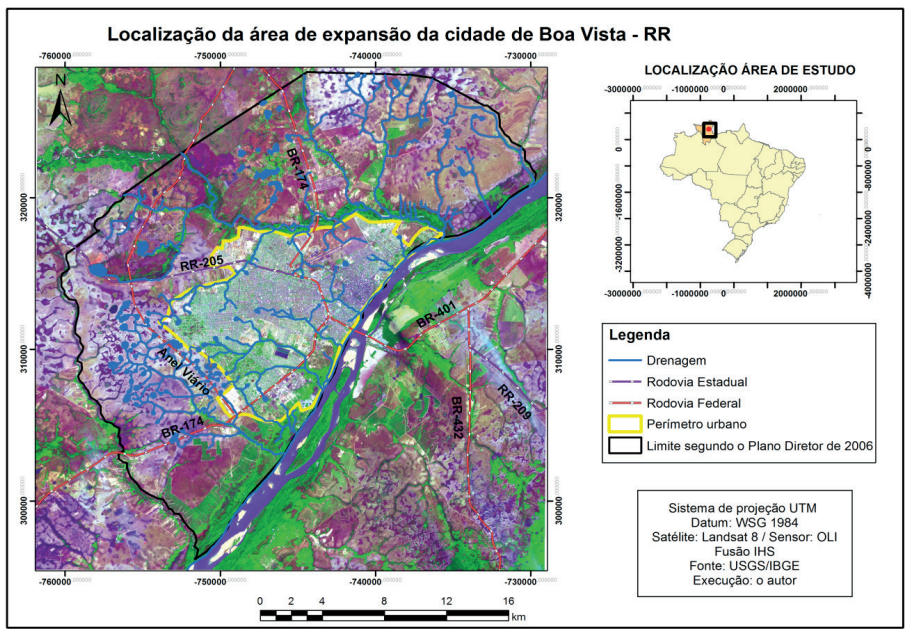

Figura 1 - Mapa de localização da área de estudo

Fonte: Araújo Júnior, 2016.

Frisa-se as imagens de satélite, pois coaduna-se com a proposta de Florenzano (2002) de que a partir de sua utilização de aspectos ligados à urbanização, como a localização do sítio urbano, limite da área e expansão urbana e o processo de conurbação² são facilmente identificados.

O conhecimento dos produtos oriundos da interpretação, processamento e elaboração de cartografias se faz importante, pois as análises, a gestão e o planejamento de cunho ambiental, econômico, social, podem implicar resultados promissores ou desastrosos. Para Fitz (2008b), estes dependerão das decisões tomadas ao longo dos procedimentos, ou seja, na fase de geoprocessamento.

Neste contexto, Rocha (2011) afirma que no plano conceitual, o geoprocessamento é um conjunto e não apenas um ramo específico das técnicas avançadas para registrar os fenômenos geográficos, o tratamento e armazenamento dos dados para a confecção de um mapa, necessitando de técnicas. A esse conjunto de técnicas, Teixeira e Christofoletti (1999) chamam de geotecnologia.

Para Câmara e Davis (2001), o Geoprocessamento utiliza técnicas matemáticas e computacionais para o tratamento da informação geográfica que vem influenciando de maneira crescente as áreas de Cartografia, Análise de Recursos Naturais, Transportes, Comunicações, Energia e 
Planejamento Urbano e Regional. As ferramentas computacionais para Geoprocessamento, chamadas de Sistemas de Informação Geográfica (SIG), permitem realizar análises complexas ao integrar dados de diversas fontes e ao criar bancos de dados georreferenciados. Tornam ainda possível automatizar a produção de documentos cartográficos, sempre com prévia supervisão para melhores resultados.

A elaboração de mapas complexos pode ser processada em ambiente computacional, desde que se conheçam as variáveis que serão inseridas no software de processamento. Assim, tem-se como objetivo analisar como o uso e cobertura do solo são ferramentas necessárias para entender o incremento populacional, para melhor planejar os usos futuros do espaço boavistense, visto que recursos naturais como corpos d'água e vegetação nativa estão se perdendo no processo de ocupação.

\section{Materiais e Métodos}

Para a elaboração dos produtos cartográficos foram utilizadas imagens Landsat 5, captadas pelo sensor TM 5 nos anos de 1985 e 1995, com resolução de 30 metros na órbita/ponto 232/58 e disponíveis no Instituto Nacional de Pesquisas Espaciais (INPE), bem como imagem do satélite CBERS-2, sensor CCD do ano de 2005 com resolução espacial de 20 metros na órbita/ponto 175/97, a qual também se encontra disponível no INPE. Já a imagem Landsat 8, sensor OLI do ano de 2014 nas resoluções de 15 e 30 metros na órbita/ponto 232/58 está disponível no site da United States Geological Survey (USGS), também sendo utilizada para o estudo.

O intervalo de 10 anos entre as imagens, deve-se ao contexto de transição política do estado de Roraima, o qual em 1985 estava sobre a tutela do governo federal brasileiro sendo Território Federal. No entanto, após 1988, com sua constituição enquanto estado da federação tem suas dinâmicas alteradas, das quais se dá destaque para o uso do solo ocorrido de 1985 a 2014 por meio dos mapas de uso e cobertura.

Os softwares utilizados foram: (i) PCI Geomatic 10.0, o qual subsidiou a correção atmosférica e geométrica das imagens dos anos de 1985, 1995 e 2005, bem como a classificação supervisionada de todas as imagens, incluindo 2014, possibilitando obter os mapas de uso e cobertura do solo; (ii) ENVI 5.0, utilizado para fundir as bandas espectrais do Landsat 8 a banda pancromática com o intuito de obter um produto de 15 metros e 16 bits, 
possibilitando a geração de um produto mais completo em razão da maior variação colorida (superior a 60.000) por meio da ferramenta Gram-Schmidt Pan Sharpening; (iii) Microsoft Office Excel 2007, utilizado para cálculos estatísticos de correção atmosférica e cálculo do OIF (Opitmum Index Factor) para obtenção das três bandas a serem utilizadas no processamento digital das imagens para formar o RGB. Pelo Excel também foram elaborados os gráficos de correção atmosférica e de uso do solo.

Assim, as mudanças espaciais de uso e cobertura no solo foram observadas a partir das imagens de satélite Landsat 5 sensor TM para os anos de 1985 e 1995, imagem CBERS-2 sensor CCD de 2005 e imagem Landsat 8 sensor OLI de 2014 (previamente geoprocessadas), perfazendo 30 anos em uma análise multitemporal, por meio do software PCI Geomatic 10.0 com o procedimento de classificação supervisionada.

Diante da análise espacial e temporal fez-se necessário a criação de classes para se observar as mudanças processadas sobre a paisagem de Boa Vista. Desta forma, cinco classes foram criadas, (i) Área urbana, (ii) Solo exposto, (iii) Vegetação ciliar para o ano de 1985 e vegetação ciliar/ secundária para os demais anos, (iv) corpos d’água e (v) savana. A classe outros foi criada automaticamente pelo software de classificação (PCI Geomatic 10.0) das imagens para designar objetos espaciais indistintos.

As nomenclaturas savana3 e solo exposto foram utilizadas, respectivamente, (i) devido tratar-se de vegetação predominante com plantas gramíneas, com árvores esparsas e arbustos isolados ou em pequenos grupos sem presença de culturas, mais semelhantes aos encontrados na África do que na região central do Brasil. A cor rosa foi utilizada para representação pois se aproxima do magenta, representação da imagem de satélite tratada e (ii) também por serem áreas sem uso, seja para a construção civil ou para usos agrícolas.

\section{Resultados e Discussão}

Uso e cobertura do solo e o processo de planejamento urbano

Para o planejamento urbano, entender as dinâmicas que ocorreram e que ocorrem sobre o espaço citadino é salutar. Considerar que tais mudanças têm reflexo não só sobre estruturas sociais, mas também sobre estruturas biofísicas como a vegetação e cursos d'água é um primeiro 
passo. Logo, a análise do uso e cobertura do solo de 1985 (Fig. 2) ajudará a compreender as modificações em curso.

Geoprocessar imagens de satélite com atenuação dos efeitos atmosféricos, escolha estatística de bandas espectrais para formar a representação RGB com melhor aproveitamento de dados e fusão de imagens de baixa resolução a imagens de alta resolução constitui-se metodologia salutar, pois permitem o melhor aproveitamento das informações da imagem com perdas reduzidas de dados e melhor apreciação do uso e cobertura do solo.

O geoprocessamento de imagens de satélite permite que se obtenham produtos melhores acabados e tenha-se, com isso, um planejamento ambiental efetivo devido ao maior aproveitamento de informações contidas na imagem, as quais se perderiam caso fossem trabalhadas em estado bruto.

Ordenar o espaço por meio de produtos cartográficos de alta qualidade permite a construção de mapas de uso e cobertura melhor definidos em seus limites e podem criar prospecções sobre possíveis intervenções que venham a ocorrer, pois em se tratando do espaço, o qual é dinâmico (social e ambientalmente), faz-se mister planejar no presente, considerando intervenções do passado, vislumbrando melhor aproveitamento no futuro.

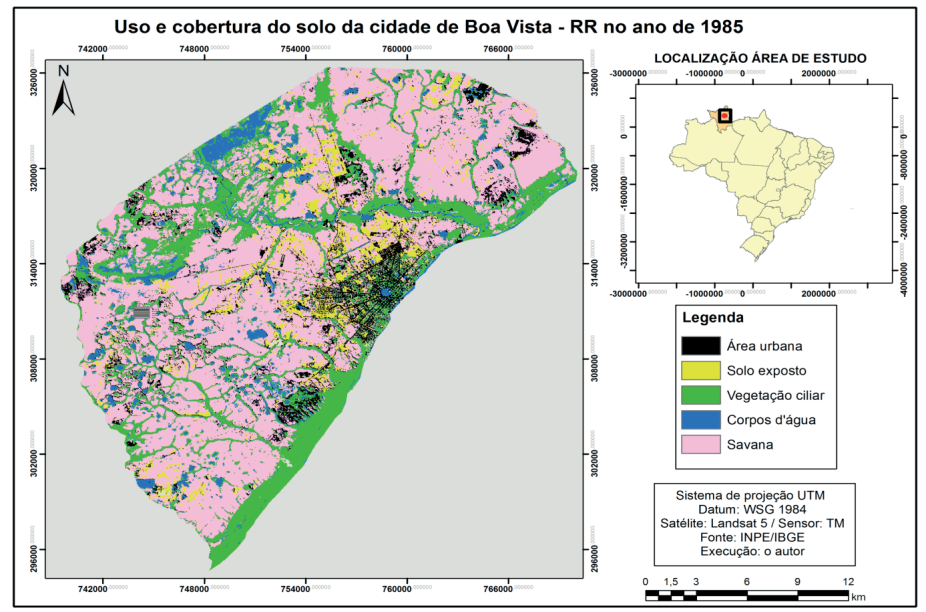

Figura 2 - Mapa de classificação do uso e cobertura do solo da área de expansão de Boa Vista a partir da imagem Landsat 5 sensor TM de 1985. 
A classificação da imagem de 1985 mostra que 8,59\% da área de estudo se apresenta urbanizada e que as classes predominantes são savana com 55,68\% de área e vegetação ciliar com 22,47\%. Apesar de a classe solo exposto apresentar percentual de 5,96\%, este se torna expressivo por se concentrar em áreas próximas ao espaço urbano, podendo indicar indícios de uso para moradia e/ou atividades ligadas ao setor primário da economia, mas que neste primeiro momento são tratadas como áreas livres de uso.

A paisagem biofísica com savanas e vegetação ciliar compunha $78,15 \%$ da área total de estudo, além da classe corpos d'água com 6,57\% com destaque para as áreas de lago, as quais se faziam presentes no perímetro urbano. A figura 3 demonstra a representatividade dos dados de uso de cobertura do ano de 1985.

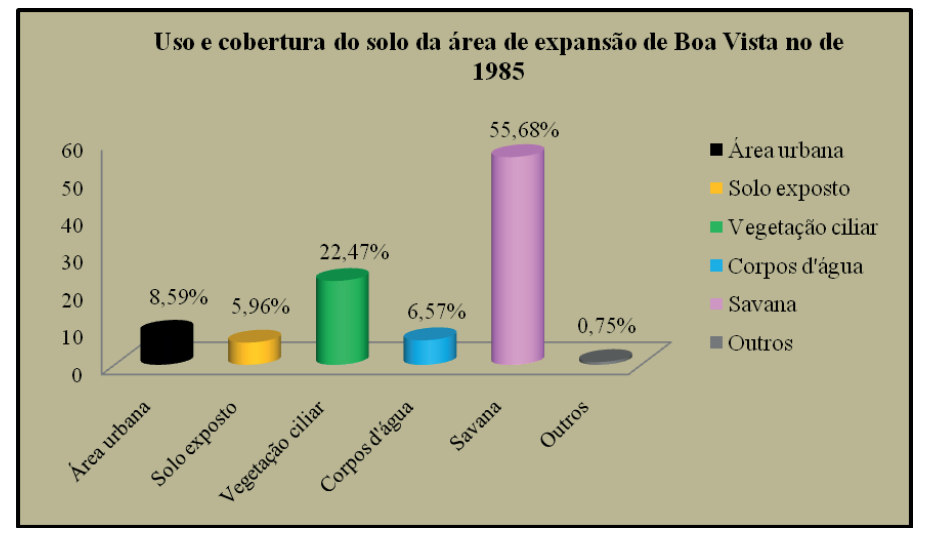

Figura 3 - Gráfico do uso e cobertura do solo de Boa Vista RR a partir da imagem Landsat 5 de 1985 sensor TM.

Fonte: Araújo Júnior, 2016.

Para Silva (2009), a expansão urbana de Boa Vista, após a década de 1980, foi produto de novas áreas que progressivamente foram incorporadas mediante a proliferação de novos loteamentos, produzidos de forma "descontrolada", respondendo especialmente a interesses políticos de assentamentos de migrantes que eram induzidos a se deslocarem para Boa Vista. A partir deste crescimento populacional começou a ocorrer uma expansão principalmente sobre a zona oeste da cidade (Fig. 4), a 
qual possuía corpos hídricos que começaram a desaparecer por conta de drenagem, com canalização de canais e principalmente aterros.

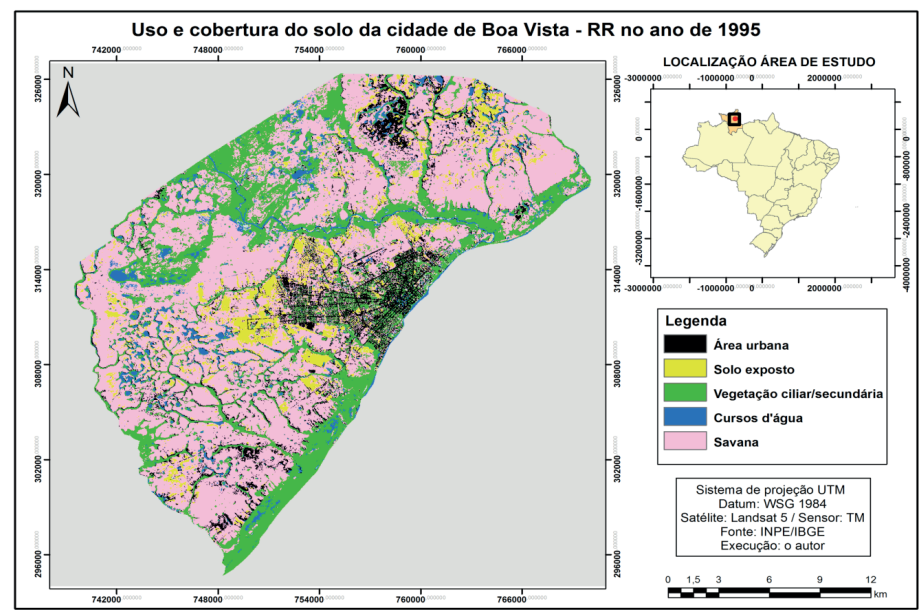

Figura 4 - Mapa de classificação do uso e cobertura do solo da área de expansão de Boa Vista a partir da imagem Landsat 5 sensor TM de 1995, denotando crescimento da área urbana à Zona Oeste.

Fonte: Araújo Júnior, 2016.

A imagem de 1995 mostra uma expansão da área urbana a qual passa a ter um percentual de 9,41\%, concomitante ao aumento da área de solo exposto que cresce para $6,31 \%$. A vegetação ciliar/secundária tem um relativo aumento, ficando em $23,16 \%$, sendo importante destacar que este aumento pode estar relacionado à proliferação de vegetação secundária de pequeno porte como gramíneas por vetores como polinização natural, formigas e pássaros, bem como, em alguns casos, vegetação de médio e grande porte, estas últimas presentes inclusive na área urbana de Boa Vista.

A figura 5 esboça os dados obtidos a partir da classificação da imagem Landsat 5 sensor TM do ano de 1995. 


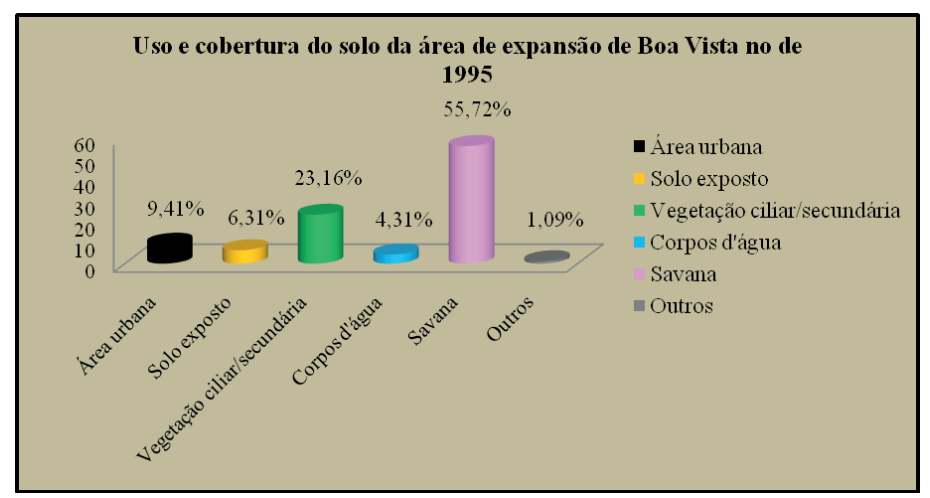

Figura 5 - Gráfico do uso e cobertura do solo de Boa Vista RR a partir da imagem Landsat 5 de 1995 sensor TM

Fonte: Araújo Júnior, 2016.

Houve uma significativa diminuição dos corpos d'água, estando à área com 4,31\%. De acordo com a figura de classificação de 1985, ocorreu uma supressão de corpos aquosos em decorrência da expansão urbana para a zona oeste da cidade de Boa Vista no ano de 1995, fato que não se aplica a savana, a qual tem seu percentual de área levemente aumentado para 55,78\%. A classificação processada na imagem CBERS-2 sensor CCD de 2005 (Fig. 6) permite com que se façam importantes considerações.

Mesmo sob a égide do Plano Diretor de 1991, os desdobramentos do crescimento urbano de Boa Vista se deram de forma desordenada. O Plano Diretor de Desenvolvimento Urbano de Boa Vista, lei Municipal $\mathrm{n}^{\circ} 244$, de 6 de setembro de 1991, instituiu as normas de promoção do desenvolvimento urbano e também a definição física do Município de Boa Vista chegando a abranger: o zoneamento; uso e ocupação do solo; sistema viário e parcelamento do solo através do ordenamento das funções sociais da cidade; entre outros.

Merece destaque a seção meio ambiente, que contemplava o desenvolvimento das atividades humanas; a preservação dos recursos naturais, históricos e arquitetônicos; e as características essenciais ambientais dentro de padrões de qualidade definidos. Afirmava ainda que o controle ambiental devesse ser efetivado por meio do monitoramento, planejamento e atos normativos, para disciplinar as atividades públicas e particulares. 
No que se referia a Preservação o artigo $38^{\circ}$ identificava inaptas à urbanização as áreas alagadiças e sujeitas a inundações, não edificáveis e de preservação permanente, as faixas de terreno situadas às margens de rios ou cursos d'água, de largura variável, como por exemplo, o igarapé Grande com faixa de preservação de setenta metros.

No entanto, Veras (2009) salienta que na elaboração do referido plano não houve uma consulta prévia à população, tão pouco uma leitura da cidade que pudesse diagnosticar as reais necessidades da população e os arranjos produtivos locais que favorecessem o desenvolvimento e crescimento ordenado do território.

Os desdobramentos do não seguimento das normativas previstas no Plano Diretor de 1991 podem ser observados na classificação de uso e cobertura do solo de Boa Vista do ano de 2005 (Fig. 6), pois a área urbana cresceu em relação ao ano de 1995 para a zona oeste, pressionando cada vez mais recursos naturais como vegetação, solo e hidrografia.

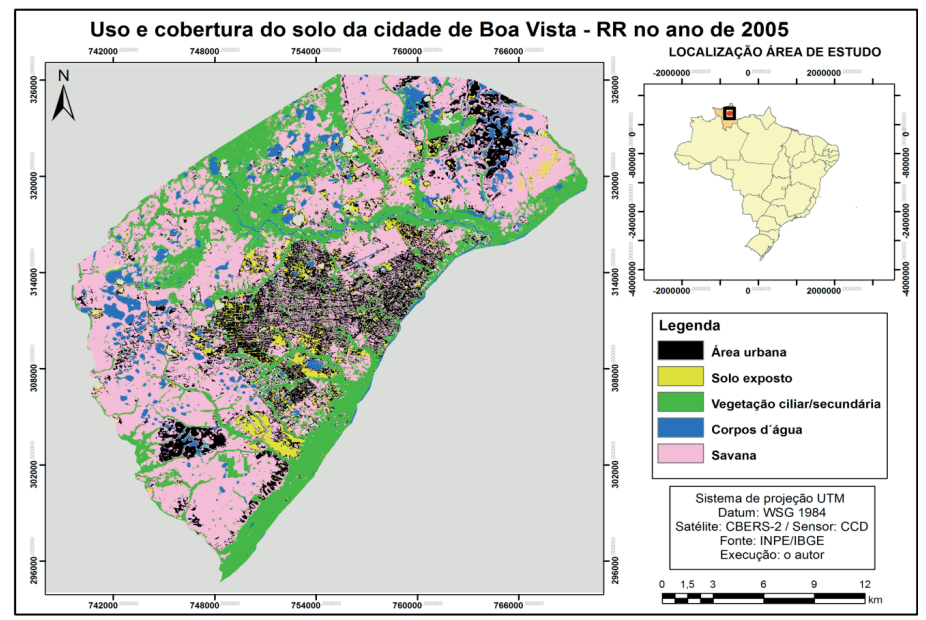

Figura 6 - Mapa de classificação do uso e cobertura do solo da área de expansão de Boa Vista a partir da imagem CBERS-2 sensor CCD de 2005, com destaque ao aumento da área urbana à Zona Oeste.

Fonte: Araújo Júnior, 2016.

O não ordenamento, no entanto, não se deve a variáveis jurídicoadministrativas, pois as mesmas encontram-se presentes por meio do 
Plano Diretor Urbano de Boa Vista (em vigor na época), e também o Código Florestal Brasileiro de 1965 e suas alterações.

A expansão urbana vista na figura 6 deve-se ao agente produtor do espaço Estado, o qual viabilizou a ocupação de áreas impróprias (em contraposição ao determinado pelo Código Florestal), como grandes planícies de inundação e áreas de nascentes, as quais foram aterradas em períodos de seca, mascarando potenciais problemáticas oriundas de cheias dos rios e altas pluviosidades.

Classificada a imagem de 2005, a distorção mais significativa é sobre a classe corpos d'água que aumentou seu percentual para 5,87\% (Fig. 7). A qualidade da imagem permitiu com que fossem visualizadas feições antes indistintas, as quais estavam cobertas por nuvens ou se assemelhavam a vegetação.

A classe outros de 1985 que estava em 0,75\%, passou para 1,09\% em 1995 e chegou a 2,71\% em 2005, revelando que mesmo com a melhoria na resolução da imagem classificada indistinções ainda se fazem presentes.

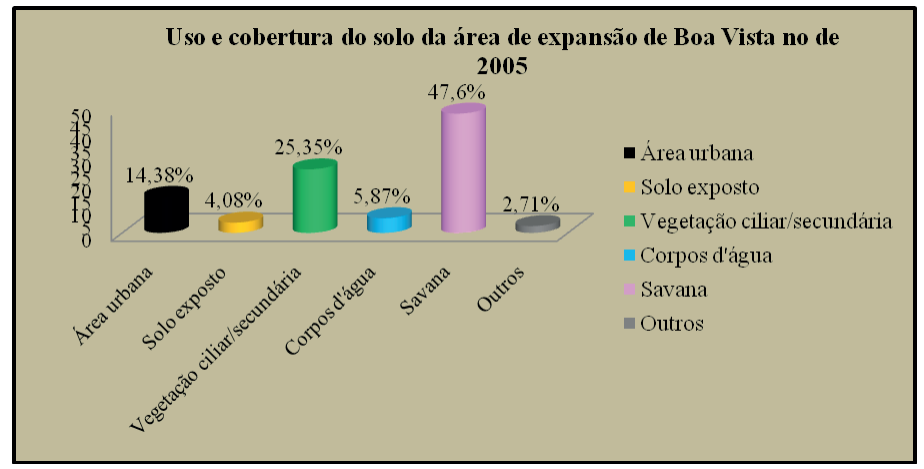

Figura 7 - Gráfico do uso e cobertura do solo de Boa Vista RR a partir da imagem CBERS-2 de 2005 sensor CCD.

Fonte: Araújo Júnior, 2016.

A área urbana cresceu para $14,38 \%$, levando a crer que houve uma ocupação de áreas de solo exposto, a qual diminuiu para 4,08\%, bem como de savana que teve uma diminuição de área de $8 \%$ passando para $47,6 \%$ no total.

As savanas conforme Vale Júnior e Schaefer (2010) ocupam uma área de aproximadamente $43.000 \mathrm{~km}^{2}$, situados na porção central do estado 
e onde está inserida a capital Boa Vista e com o passar dos anos percebe-se um avanço urbano sobre esta formação vegetal conforme mostra a figura 6 .

O crescimento populacional na cidade de Boa Vista entre os anos de 1995 e 2005 segundo Veras (2009), se deve em parte, nos anos 2000 à política adotada por Ottomar de Souza Pinto, então prefeito, que ao incentivar o setor agrícola e a migração atraí muitas pessoas oriundas da região Nordeste e Centro-Sul do país para a cidade de Boa Vista, com a promessa de casa própria e emprego.

Tal crescimento fez com que áreas ocupadas precariamente começassem a receber equipamentos urbanos necessários ao deslocamento e lazer. Veras (2009) destaca que durante o mandato da prefeita Teresa Jucá, iniciado em 2005, houve a construção do Terminal de Integração João Firmino Neto (Fig. 8A), no bairro Caimbé (hoje desativado) e a construção de áreas de lazer como a Vila Olímpica no bairro Olímpico (Fig. 8B), atendendo diretamente os moradores dos bairros Senador Hélio Campos, Cambará, Nova Cidade, Pintolândia e Asa Branca, bem como a construção do Parque Germano Augusto Sampaio (Fig. 8C) no bairro Pintolândia, com 177 m².
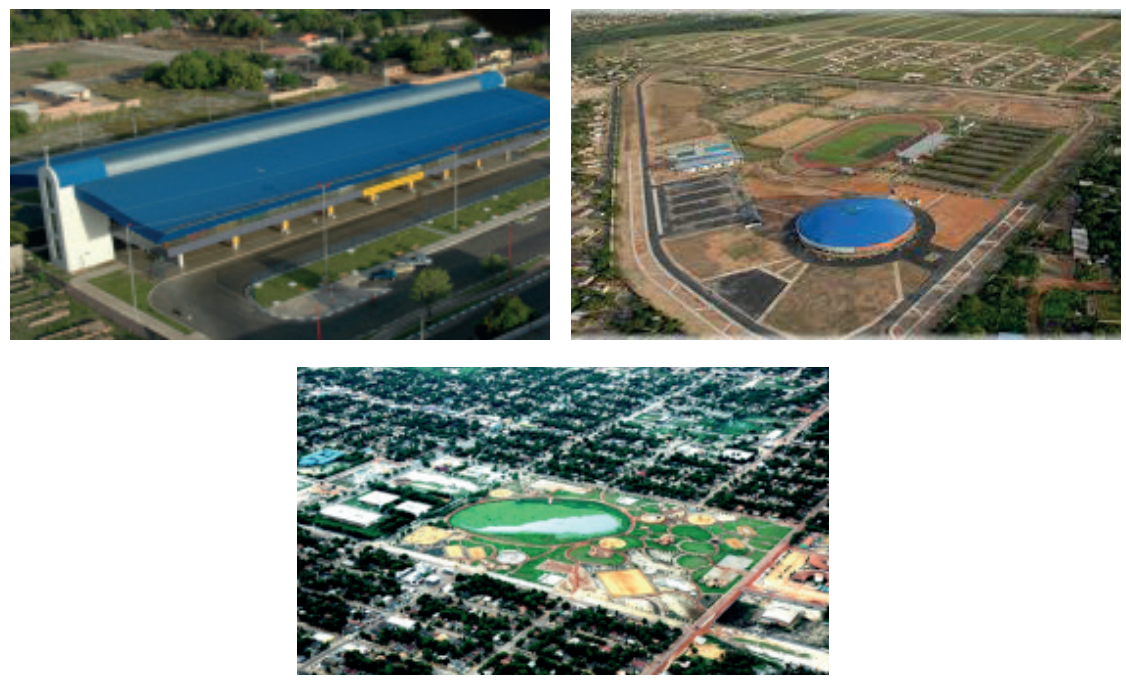

Figura 8 - A) Terminal de Integração João Firmino Neto. B) Vila Olímpica no bairro Olímpico e C) Vista panorâmica do Parque Germano Augusto Sampaio.

Fonte: A) Tiago Onhuela, 2013. B) http://www.skyscrapercity.com/showthread. php?t= 1567507\&page=8, 2014 e C) Alfredo Maia, 2015. 
Áreas antes ocupadas de forma precária ganham condições de ocupação qualitativa e atraem novos moradores, oriundos de migração, os quais passam a procurar esta nova zona da cidade, no caso, a zona oeste como moradia. A zona oeste da cidade passara a atrair mais moradores, adensando a malha urbana de Boa Vista em anos seguintes, como mostra a classificação da imagem Landsat 8 sensor OLI do ano de 2014 (Fig. 9).

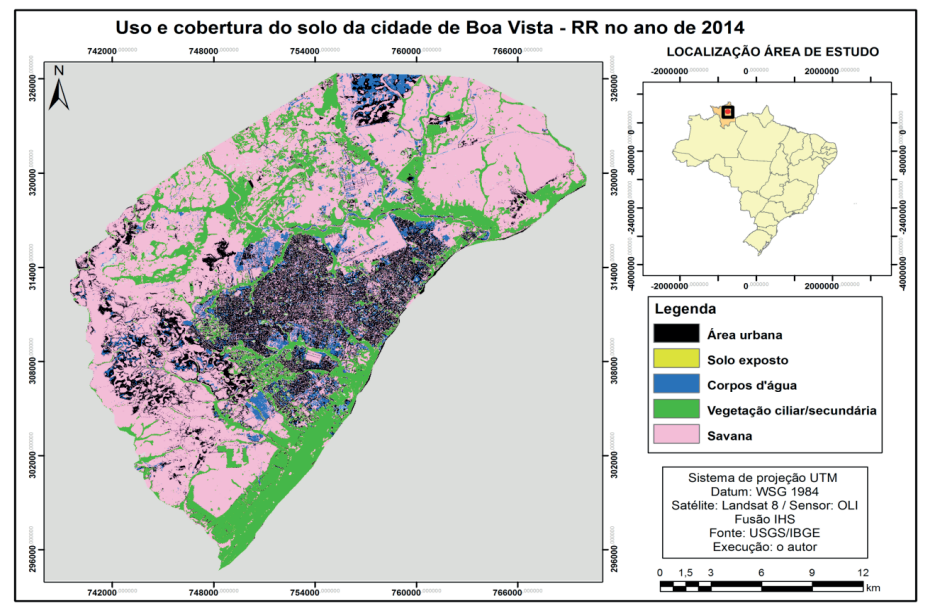

Figura 9 - Mapa de classificação do uso e cobertura do solo da área de expansão de Boa Vista

- RR a partir da imagem Landsat 8 sensor OLI de 2014, com adensamento da área urbana.

Fonte: Araújo Júnior, 2016.

No ano de 2014 percebe-se um severo adensamento urbano na cidade de Boa Vista, a qual passa de uma área ocupada de 14,38\% em 2005 para $16,17 \%$ em 2014. Nos bairros da zona oeste a consolidação de infraestrutura foi latente. Como exemplo Veras (2009) destaca o bairro Centenário com um programa de urbanização que incluiu a construção de 273 casas, 50 banheiros, 200 fossas sépticas, reforma de 40 moradias, duplicação e asfaltamento de vias, construção de rotatórias de segurança e 4.160 metros de calçadas e sarjetas, ou seja, houve um fomento a ocupação dessa área.

Veras (2009) ainda afirma que houve continuidade ao trabalho de asfalto e calçamento, executando-se $285 \mathrm{~km}$ de asfalto em 639 ruas e avenidas da capital e $117 \mathrm{~km}$ de calçadas em vários bairros. A figura 10 mostra com especificidade estas implantações. 
Figura 10 - Quadro da pavimentação e calçamento de vias com destaque para os bairros da zona oeste.

\begin{tabular}{|c|c|c|c|c|c|}
\hline Bairro & $\begin{array}{c}\text { Pavimentação } \\
(\mathbf{k m})\end{array}$ & $\begin{array}{c}\text { Calçamento } \\
(\mathbf{k m})\end{array}$ & Bairro & $\begin{array}{c}\text { Pavimentação } \\
(\mathbf{k m})\end{array}$ & $\begin{array}{c}\text { Calçamento } \\
\text { (km) }\end{array}$ \\
\hline 13 de Setembro & 6 & - & Jardim Caranã & 15 & - \\
\hline 31 de Março & - & $440 \mathrm{~m}$ & Jardim Floresta & 38 & 6,020 \\
\hline Aeroporto & 16 & 2,120 & Jardim Primavera & 32 & $130 \mathrm{~m}$ \\
\hline Alvorada & 16 & 2,950 & Jardim Tropical & - & 1,620 \\
\hline Aparecida & 6 & $415 m$ & Jóquei Clube & 20 & - \\
\hline Asa Branca & 1 & - & Liberdade & 1 & 4,200 \\
\hline Bela Vista & 19 & - & Mecejana & 11 & 8,405 \\
\hline Dos Estados & - & 1,265 & Nova Canaã & 11 & 1,460 \\
\hline Buritis & 11 & 5,550 & Nova Cidade & 11 & - \\
\hline Caçari & 13 & - & Operário & 2,420 & - \\
\hline Caetano Filho & 2 & - & Paraviana & 31 & - \\
\hline Caimbé & 13 & 4,800 & Pintolândia & 27 & 3,950 \\
\hline Calungá & 6 & 3,220 & Piscicultura & 12 & $800 m$ \\
\hline Cambará & 6 & $815 m$ & Pricumã & 1 & 2,280 \\
\hline Canarinho & 1 & - & Raiar do Sol & 15 & 9,280 \\
\hline Caranã & 24 & 8,120 & Santa Luzia & 5 & 2,720 \\
\hline Cauamé & 38 & - & Santa Tereza & 26 & 2,730 \\
\hline Centenário & 17 & - & São Francisco & 1 & 1,890 \\
\hline Centro & - & 4,775 & São Vicente & 9 & 4,450 \\
\hline Cidade Satélite & - & $450 \mathrm{~m}$ & Sen. Hélio Campos & 17 & $960 \mathrm{~m}$ \\
\hline Cinturão Verde & 33 & - & Tancredo Neves & 10 & 6,570 \\
\hline Dr. Silvio Boltelho & 3 & 9,790 & Cidade Satélite & 1 & - \\
\hline Dr. Silvio Leite & 21 & - & União & 17 & $900 \mathrm{~m}$ \\
\hline Equatorial & 6 & 4,460 & - & - & - \\
\hline
\end{tabular}

O processo de crescimento da cidade de Boa Vista é estimulado por parte da prefeitura em direção a zona oeste, podendo-se observar na figura 10 que dos 47 bairros listados com intervenções de infraestrutura urbana, 32 pertencem a referida zona. Dos $571,42 \mathrm{~km}$ de asfaltamento na cidade, $442,42 \mathrm{~km}$ de asfalto foram implantados na zona oeste e dos $104,315 \mathrm{~km}$ de calçamento, $88,51 \mathrm{~km}$ de calçadas foram construídas nesta região. 
O avanço da área urbana de Boa Vista pode ser visto na figura 11.

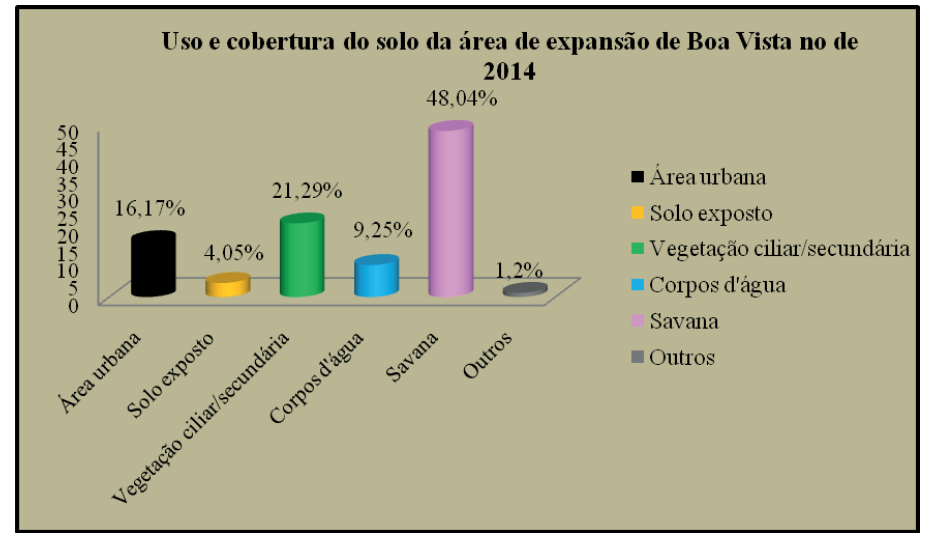

Figura 11 - Gráfico do uso e cobertura do solo de Boa Vista RR a partir da imagem Landsat 8 de 2014 sensor OLI.

Fonte: Araújo Júnior, 2016.

É relevante ressaltar que o tamanho da área de estudo, associado à resolução espectral das imagens fez que a qualidade da classificação fosse melhorando. Seguindo o coeficiente Kappa, a classificação da imagem de 1985 teve índice 0,74, considerado muito bom; da imagem do ano de 1995 obteve-se o índice 0,69, também muito bom; da imagem do ano de 2005 o índice foi de 0,75, também considerado muito bom; enquanto que a classificação do ano de 2014 apresentou índice de 0,84, o qual é considerado excelente. A discrepância entre os dados revelam o grau de acurácia das classificações.

Os dados apresentados revelam que houve aumento da classe corpos d'água (9,25\%), bem como da classe savana $(48,04 \%)$, as quais podem estar associadas à indistinção de classes em imagens de qualidade inferior, visto que a imagem Landsat 8 sensor OLI apresenta resolução de 15 m, viabilizando a identificação mais acurada dos alvos.

Para os corpos d'água é importante observar sua presença quase que exclusiva nos arredores da cidade e nas proximidades de seus limites de expansão. Isso aponta para a pressão sobre os corpos d'água, repetindo dinâmicas semelhantes ocorridas em anos anteriores em Boa Vista, fortemente atreladas a aterros e canalizações, as quais ocasionaram a significativa redução destes espaços naturais no meio urbano. 
Não só os corpos d'água deixarão de existir caso políticas de planejamento efetivas não sejam discutidas e implantadas, pois as savanas que ao longo dos últimos 30 anos apresentaram recrudescimento também terão sua margem de área diminuída.

A partir dos dados anteriormente apresentados percebe-se que houve uma diminuição da classe solo exposto, a qual reduziu para 4,05\%, bem como da classe vegetação ciliar/secundária que conta com 21,29\% de área para o ano de 2014.

A ocupação sobre áreas próximas ou mesmo dentro das planícies de inundação dos cursos d'água obriga a retirada de cobertura vegetal, a qual é essencial para manter o equilíbrio hidrológico da bacia hidrográfica. $\mathrm{O}$ que se percebe nestes 30 anos é que a cobertura vem oscilando entre diminuição e aumento, podendo estar associado ao surgimento de vegetação secundária, bem como sua posterior retirada para implantação de usos diversos, para além da moradia em si.

Os dados analisados de 1985, 1995, 2005 e 2014 mostram um processo dinâmico do uso do solo na cidade de Boa Vista, o qual foi acompanhado de perto pelo poder público municipal por meio da criação de planos diretores (BOA VISTA, 1991; 2006) e do seguimento de leis, como as do Código Florestal Brasileiro (BRASIL, 1965, 2012).

No entanto, a não eficácia destes mecanismos legais apontam para iniciativas mais incisivas do poder público junto à população, por meio de políticas públicas que de fato ordenem o uso do solo e assim comprometam de forma menos agressiva a cobertura do mesmo, inclusive atenuando impactos negativos relativos a inundações, as quais são recorrentes na cidade e atingem principalmente áreas localizadas em planície de inundação e nascentes, as quais tiveram seu processo de ocupação estimulado ao longo da história.

Não foi foco do presente estudo discutir as inundações urbanas que ocorrem na cidade de Boa Vista, todavia, um primeiro momento para se mapear áreas susceptíveis à inundação é entender o contexto de uso e cobertura do solo no tempo para melhor compreensão das marcas deixadas no espaço.

Assim, os resultados mostram que elementos como redução dos corpos d'água, retirada e supressão da vegetação associados à ocupação de áreas impróprias, potencializam a exposição da população a áreas de risco ambiental, eminentemente os relacionados à inundação, sendo 
necessário posteriormente mapear tais áreas para comparar com os dados atuais, viabilizando com um isso um melhor diagnóstico sobre o processo de uso e ocupação do espaço de Boa Vista minimizando os impactos relacionados à inundação.

Do ponto de vista metodológico a qualidade das imagens acabou por influenciar o resultado da classificação de sensores com melhores resoluções que o sensor TM das imagens de 1985 e 1995, as quais são de 30 m. A imagem CBERS-2 sensor CCD com resolução de 20 m permitiu uma melhor visualização das feições da paisagem, e um melhor trabalho do produto, revelando mais detalhes do espaço transformado.

O sensor OLI, responsável pela obtenção das imagens do ano de 2014 com resolução de 15 m permitiram uma melhor interpretação em razão do maior nível de detalhe. Justifica-se que a utilização de imagens de diferentes sensores foi por conta da menor interferência da cobertura de nuvens, fator limitante no caso de sensores passivos.

Para tanto, com o avanço tecnológico, imagens gratuitas de sensores passivos tornam-se mais frequentes e sua utilização pode ser mais frequente em escala de detalhe, diminuindo custos, principalmente em países em desenvolvimento que tem dificuldades financeiras para obtenção de imagens de alta resolução.

As limitações metodológicas por conta da resolução das distintas imagens obtidas não desabonam os resultados obtidos, pois as análises apresentaram classificação de "muito boa" a "excelente" de acordo com o índice de acurácia pelo coeficiente Kappa (já exposto anteriormente), recomendando-se assim atualizações analíticas posteriores com a metodologia empregada para comparação de dados e utilização no processo de expansão do uso e ocupação do espaço da cidade de Boa Vista.

\section{Considerações finais}

Os dados apresentados mostram que o uso e cobertura do solo são uma importante variável a ser considerada para o planejamento urbano, pois englobam o processo de adensamento urbano aos elementos naturais presentes no espaço (vegetação, solo, hidrografia).

Todavia, percebe-se que não há uma consideração de variáveis físicas e humanas associadas para se planejar o espaço urbano de forma a minimizar a ocupação e o uso de áreas potencialmente sensíveis a 
serem impactadas negativamente por inundações, com perdas materiais e até humanas.

Análises multitemporais ajudam a compreender o rumo do processo de uso no espaço, indicando quais recursos estão sendo mais degradados e quais estão diminuindo. Este elemento possibilita criar a curto e médio prazo medidas contentivas de avanço sobre espaços vulneráveis ambientalmente, minimizando impactos negativos sobre a sociedade.

A prevenção é o elemento fundamental para lidar com o risco à inundação. Além disso, com a posse de dados que mostrem quais áreas são mais susceptíveis a este risco torna-se possível atuar de forma contundente na apresentação de medidas mitigadoras e reparatórias sobre a população atingida, bem como trabalhar a médio e longo prazo em espaços formais (escolas) e não formais (como associação de moradores e igrejas) de ensino para a sensibilização no tocante a ocupação do uso do solo.

O planejamento ambiental eficiente deve considerar que políticas públicas devem ter a sociedade como atuante no processo de gestão, ou seja, como membro atuante em processos de diagnóstico, planejamento e manejo espacial, sempre tendo em conta que a sociedade se apropria da natureza e ao fazer isso a modifica de forma positiva para seu melhor habitar, bem como de forma negativa, ao gerar e/ou potencializar áreas de risco, como à inundação.

\section{Notas}

1 Enquanto os mapas contêm informação, as imagens obtidas de sensores remotos contêm dados brutos, que só se tornam informação após a sua interpretação (FLORENZANO, 2002, p. 33).

2 Conurbação é a unificação da malha urbana de duas ou mais cidades, em consequência de seu crescimento geográfico. Geralmente esse processo dá origem à formação de regiões metropolitanas. Contudo, o surgimento de uma região metropolitana não é necessariamente vinculado ao processo de conurbação.

3 A terminologia de fato seria lavrado, expressão denominada para designar áreas abertas e é utilizado pelos moradores de Roraima, segundo Carvalho (2009) com três aspectos que habilitam seu uso corrente, (i) área geográfica específica, (ii) identidade própria de Roraima e (iii) conjunto de característica ecológica e geomorfológica. Tal nomenclatura não é utilizada, devido não haver "validação" científica para tal. Sendo assim o termo mais próximo do ponto de vista fitofisionômico é savana. 


\section{Referências}

ARAÚJO JÚNIOR, A. C. R. Uso do solo e risco à inundação na cidade de Boa Vista-RR. 140 f. Dissertação (Mestrado em Recursos Naturais) - Programa de PósGraduação em Recursos Naturais, Universidade Federal de Roraima, Boa Vista, 2016.

BOA VISTA. Lei n. 924, de 28 de novembro de 2006. Dispõe sobre o plano diretor estratégico e participativo de boa vista e dá outras providências. Diário Oficial do Município de Boa Vista, RR, 30 out. 2006.

. Lei $\mathrm{n}^{0}$ 244, de 06 de setembro de 1991. Dispõe sobre a promoção do desenvolvimento urbano, zoneamento, uso e ocupação do solo, sistema viário, parcelamento do solo e dá outras providências. Diário Oficial da República Federativa do Brasil, Brasília, DF, 06 set. 1991.

BRASIL. Lei $\mathrm{n}^{\mathrm{O}}$ 12.651, de 25 de maio de 2012. Dispõe sobre a proteção da vegetação nativa e dá outras providências. Diário Oficial da República Federativa do Brasil. Brasília, DF, 28 maio 2012.

. Lei $\mathrm{n}^{\mathrm{O}}$ 4.771, de 15 de setembro de 1965. Institui o novo código florestal. Diário Oficial da República Federativa do Brasil. Brasília, DF, 15 set. 1965.

CÂMARA, G.; DAVIS, C. Introdução. In: CÂMARA, G.; DAVIS, C.; MONTEIRO, A. M. V. (Org.). Introdução a ciência da Geoinformação. Ministério da Ciência e Tecnologia - Instituto de Pesquisas Espaciais (INPE), São José dos Campos, 2001. 5 p.

CARVAlHO, C. M. O lavrado da Serra da Lua em Roraima e perspectivas para estudos da herpetofauna na Região. Revista Geográfica Acadêmica v.3, n.1. p. 4-17, 2009.

FITZ, P. R. Cartografia básica. São Paulo: Oficina de Textos, 2008a. 143 p. $\overline{160 \mathrm{p} .}$

Geoprocessamento sem complicação. São Paulo: Oficina de Textos, 2008b.

FLORENZANO, T. G. Imagens de satélite para estudos ambientais. São Paulo: Oficina de Textos, 2002. 97 p.

IBGE. INSTITUTO BRASILEIRO DE GEOGRAFIA E ESTATÍSTICA. Censo Demográfico. Disponível em < www.ibge.gov.br>. Acesso em: 10 set. 2016.

INPE. INSTITUTO NACIONAL DE PESQUISAS ESPACIAIS. Catálogo de imagens. Disponível em < http://www.dgi.inpe.br/CDSR/ >. Acesso em: 12 ago. 2015.

JOLY, F. A cartografia. Campinas SP: Papirus, 1990. 136 p.

ROCHA, A. A. Sociedade e natureza: a produção do espaço urbano em bacias hidrográficas. Vitória da Conquista: Edições UESB, 2011. 156 p.

SILVA, P. R. F. Boa Vista: gênese espontânea e gênese induzida. Acta Geográfica, Boa Vista, v. 1, n. 5, p. 63-71, 2009. 
TEIXEIRA, A.; CHRISTOFOlETTI, L. A. Sistema de Informações Geográficas. São Paulo: Hucitec, 1999. 121 p.

USGS. UNITED STATES GEOLOGICAL SURVEY. EarthExplorer. Disponível em $<$ https://earthexplorer.usgs.gov/ >. Acesso em 10 de ago. 2015.

VALE JÚNIOR, J. F.; SCHAEFER, C. E. G. R. Solos sob savanas de Roraima: gêneses, classificação e relação e relações ambientais. Boa Vista: Gráfica Ioris, 2010. 219 p.

VERAS, A. T. R. A produção do espaço urbano e Boa Vista - Roraima. 2009. 235 f. Tese (Doutorado em Geografia Humana) - Departamento de Geografia da Faculdade de Filosofia, Letras e Ciências Humanas da Universidade de São Paulo, São Paulo, 2009.

Antônio Carlos Ribeiro Araújo Júnior - Geógrafo e especialista em Educação para a Gestão Ambiental pela Universidade Federal do Pará, mestre em Recursos Naturais pela Universidade Federal de Roraima e doutorando em Geografia pela Universidade Federal Fluminense. Professor assistente I do Departamento de Geografia da Universidade Federal de Roraima.

Stélio Soares Tavares Júnior - Bacharel em Geologia pela Universidade Federal do Pará, mestre em Geologia e Geoquímica pela Universidade Federal do Pará e doutor em Sensoriamento Remoto pelo Instituto Nacional de Pesquisas Espaciais. Atualmente é professor associado IV do Departamento de Geologia da Universidade Federal de Roraima.

Os autores ofereceram substanciais contribuições científicas e intelectuais ao estudo. As tarefas de concepção e design do estudo, preparação e redação do manuscrito, bem como a revisão crítica foram desenvolvidas em parceria. O primeiro autor ficou especialmente responsável pelo desenvolvimento teórico-conceitual. Os dois autores se responsabilizaram pela aquisição de dados e suas interpretações e análises, bem como pelos procedimentos técnicos e tradução dos resumos artigo. 